\title{
Model Hydrodesulfurization Catalysts: Solid State Synthesis and Characterization of Iron Containing Molybdenum Sulphide
}

\author{
M.A. VILLA GARCIA \\ Dpto. Química Organometálica, Facultad de Química, Universidad de Oviedo, Oviedo-33071 \\ (Spain) \\ and \\ J. LINDNER, A. SACHDEV and J. SCHWANK* \\ Department of Chemical Engineering, The University of Michigan, Ann Arbor, MI 48109-2136. \\ (USA)
}

(Received 14 June 1989, revised manuscript received 7 August 1989)

\section{ABSTRACT}

Model catalysts for hydrodesulfurization were synthesized via solid state reactions of elemental sulfur with metallic iron and molybdenum powders. The starting materials had a general strichiometry of $\mathrm{Fe}_{2 \alpha} \mathrm{Mo}_{1-\alpha} \mathrm{S}_{2}$ with $\alpha$ between 0.025 and 0.3 . X-ray diffraction and selected-area electron diffraction were used to characterize the solid phases formed both before and after exposure to typical reaction conditions. Catalytic activity for the hydrodesulfurization of thiophene was tested in a flow reactor and high activity coincided with the presence of a non-stoichiometric, sulfurdeficient molybdenum sulfide phase.

\section{INTRODUCTION}

Although it is well known that the activity of $\mathrm{MoS}_{2}$ for sulfur removal from petroleum feedstocks can be considerably enhanced by the addition of Group VIII metals such as cobalt and nickel, there is no agreement among the different research groups regarding the nature of the active sites and the fundamental basis of the promotional effect. Different structural models have been proposed to describe the chemical state of the promoter and the interactions that are believed to take place between the promoter and molybdenum in the sulfided hydrodesulfurization (HDS) catalysts [1-11]. A prominent model at this time is that of Topsøe et al. [12,13], who found a correlation between the HDS activity and the presence of a "Co-Mo-S" phase. Other researchers have obtained evidence in support of this model using EXAFS (extended X-ray absorption fine structure) [9] and electron microprobe studies [14,15]. The CoMoS species may be viewed as a $\mathrm{MoS}_{2}$ phase with covalently bonded cobalt 
ions located at the edges of the $\mathrm{MoS}_{2}$ hexagonal lattice. Though the edge plane terminology is imprecise in the strictest crystallographic sense, the concept is used regularly in the HDS literature. Yet, despite this large effort devoted to determining the structure of the active phase, there are still many unanswered questions about its specific nature, the precise meaning of an edge plane in a material as anisotropic as $\mathrm{MoS}_{2}$, and the physicochemical properties of the promoter.

The role of iron as a promoter [16-20] has received much less attention than either cobalt or nickel. Some researchers have reported a negative promoting effect of iron [18] while others have found the promotion to be positive, though considerably less pronounced than that of cobalt or nickel $[16,19]$. The most widely used materials have been cobalt or nickel promoted molybdenum sulfides, as they are believed to be the most active and least expensive of the transition metal sulfides [21]. Iron has not been used as a promoter industrially because it has been demonstrated to exhibit less of a promoting effect than cobalt or nickel $[22,23]$. In addition to this, theoretical models have been developed $[18,24]$ which support these empirical findings. In these theoretical studies it was postulated that the promoting effect of nickel and cobalt may be traced to the electron transfer capabilities of the cobalt-molybdenum and nickel-molybdenum systems in which the molybdenum is formally reduced relative to the molybdenum in $\mathrm{MoS}_{2}$. The same model applied to the ironmolybdenum catalyst system revealed that the electronic configuration of molybdenum would not be greatly effected by the presence of iron, and hence little additional catalytic activity may be expected by incorporating iron into a molybdenum sulfide system.

The aim of this work is to study the effect of iron in catalysts prepared by solid state synthesis in comparison with the effect of cobalt in a similar solid state catalyst system [25]. In this previous study, enhanced HDS activity coincided with the presence of a non-stoichiometric molybdenum sulfide phase, and it was found that the main role of cobalt in this system was to facilitate the formation of a sulfur deficient phase. Related studies carried out with copper [26] and nickel [27] have yielded similar results, i.e. that the addition of the second metal to the molybdenum sulfide synthesis charge led to the formation of a nonstoichiometric, sulfur-deficient molybdenum sulfide phase.

\section{EXPERIMENTAL}

\section{Sample preparation}

The synthesis of a series of different bulk $\mathrm{Fe}-\mathrm{Mo}-\mathrm{S}$ phases was based on solid state reactions of elemental sulfur with metallic iron and molybdenum powders, assuming an iron valence of $2+$ and a molybdenum valence of $4+$ in keeping with the electron paramagnetic resonance (EPR) data [28]. Solid 
state synthesized bulk phases are easier to characterize than HDS catalysts prepared by conventional means [29-31] and require no thermal or sulfiding pretreatment prior to activity studies.

Six unsupported iron promoted catalysts with an overall stoichiometry of $\mathrm{Fe}_{2 \alpha} \mathrm{Mo}_{1-\alpha} \mathrm{S}_{2}$ where $\alpha$ was between 0.025 and 0.3 were prepared by solid state reactions of the elements. These catalysts with different iron-to-molybdenum ratios were prepared by combining $\alpha$ moles of iron and $(1-\alpha) / 2$ moles of molybdenum per mole of sulfur. The three chemicals used for the preparation were Fluka products (purum). The metallic iron and molybdenum powders were thoroughly mixed with elemental sulfur by grinding them together to insure intimate mixing of the components. The mixtures were placed into quartz tubes which were then evacuated to about $0.1 \mathrm{~Pa}$ and sealed. The tubes containing the mixtures were heated at a heating rate of $10 \mathrm{~K}$ per minute from room temperature to $783 \mathrm{~K}$, held at this temperature for 24 hours, and then rapidly quenched. Once the treatment was finished, the quartz tubes were opened and the dark grey or black powdered materials were removed. Based on the amounts of elemental powders used for the synthesis, the samples were named $\mathrm{Fe}_{0.05} \mathrm{Mo}_{0.975} \mathrm{~S}_{2}, \mathrm{Fe}_{0.1} \mathrm{Mo}_{0.95} \mathrm{~S}_{2}, \mathrm{Fe}_{\mathrm{Fe} 0.2} \mathrm{Mo}_{0.9} \mathrm{~S}_{2}, \mathrm{Fe}_{0.5} \mathrm{Mo}_{0.75} \mathrm{~S}_{2}, \mathrm{Fe}_{0.4} \mathrm{Mo}_{0.8} \mathrm{~S}_{2}$ and $\mathrm{Fe}_{0.6} \mathrm{Mo}_{0.7} \mathrm{~S}_{2}$. The unpromoted $\mathrm{MoS}_{2}$ and two non-stoichiometric samples, $\mathrm{MoS}_{1.95}$ and $\mathrm{MoS}_{1.99}$, were prepared from a mixture of metallic molybdenum and elemental sulfur following the same procedure.

In addition to this, a mechanical mixture of metallic iron and molybdenum powders with an iron-to-molybdenum atomic ratio of 0.222 was prepared and then sulfided under standard presulfiding conditions for conventional catalysts (at $673 \mathrm{~K}$ for 24 hours in a flow of $2 \% \mathrm{H}_{2} \mathrm{~S} / \mathrm{H}_{2}$ ). This sample was named $\mathrm{Fe}_{0.2} \mathrm{Mo}_{0.9}+\mathrm{H}_{2} \mathrm{~S}$.

\section{Catalyst characterization}

X-ray diffraction patterns of all the samples were obtained using a Phillips PW-1729 powder diffractometer equipped with a graphite crystal monochromator and $\mathrm{Cu} \mathrm{K}$ alpha radiation. The surface areas of the freshly prepared samples were determined by using the BET method and a Monosorb Quantachrome Single Point instrument with nitrogen as adsorbate.

Electron microscopy was used to obtain selected-area electron diffraction patterns of small regions of the catalysts, complementing the $\mathrm{X}$-ray diffraction study. A JEOL $2000 \mathrm{FX}$ microscope operating at $200 \mathrm{kV}$ was utilized for this purpose. Convergent beam diffraction patterns were taken using a 70 or 120 $\mu \mathrm{m}$ condenser aperture, while selected-area diffraction patterns were obtained from regions $20 \mu \mathrm{m}$ in diameter. A JEOL $4000 \mathrm{EX}$ microscope operating at 400 $\mathrm{kV}$ was used to obtain high resolution micrographs which provided us with information at the atomic resolution level. Specimens were prepared by crushing the catalyst powder and then suspending it in isopropyl alcohol by soni- 
cating the resulting mixture for 10 minutes. A few drops of this suspension were applied to a holey carbon support film on a copper grid.

\section{Activity measurements}

The catalytic activity for the hydrodesulfurization of thiophene (Aldrich $99 \%+$, Gold Label) was measured in a $1 / 4$ inch diameter stainless-steel continuous flow reactor. The powdered catalyst $(0.35 \mathrm{~g})$ was loaded into the reactor and the temperature raised to $673 \mathrm{~K}$ under a flow of high-purity helium at $30 \mathrm{ml}$ per minute and held at $673 \mathrm{~K}$ for 30 minutes. Then, the temperature was lowered to the desired reaction temperature, typically between 473 and $673 \mathrm{~K}$. The He flow was replaced by a gaseous feed stream containing $2.7 \%$ (by volume) of thiophene, the balance being hydrogen, at a flow rate of $10 \mathrm{ml}$ per minute and a pressure of $98.6 \mathrm{kPa}$. The high-purity helium and hydrogen $(<49$ ppm impurities) were further purified by passage through a commercial oxygen trap (Matheson) and a bed of molecular sieves (5A) to remove moisture. Although XPS of the fresh catalysts showed that exposure to air during loading created a small amount of surface oxide species, the reducing environment of the reactant stream was sufficient to eliminate any of these oxide species. Over periods up to 20 hours on-stream no significant deactivation was observed.

The effluent from the reactor was analysed periodically by gas chromatography. Product separation and analysis were performed by using an n-octane/ Porasil $\mathrm{C}$ column in a Varian 3700 gas chromatograph equipped with a thermal conductivity detector. Peak areas were determined with a Hewlett Packard $3390 \mathrm{~A}$ integrator. After a given catalytic run the catalyst bed was flushed with helium gas at $673 \mathrm{~K}$. The activity measurements were normalized in terms of moles of thiophene converted per mole of molybdenum per second. There is no unambiguous measure for the actual number of active surface sites. Therefore, these activities will henceforth be referred to as quasi-turnover frequencies.

\section{RESULTS AND DISCUSSION}

The X-ray powder diffraction patterns of the iron-containing catalysts before being used in the HDS reaction are given in Fig. 1. The diffraction patterns of the unpromoted $\mathrm{MoS}_{2}$ and $\mathrm{MoS}_{1.99}$ samples are also included. The diffraction pattern of $\mathrm{MoS}_{1.95}$ is not shown in this figure, as it was identical to that of $\mathrm{MoS}_{1.99}$ with the exception of a peak at $2 \theta \sim 42^{\circ}$ resulting from the Mo (110) reflection. This peak in the $\mathrm{MoS}_{1.95}$ sample was due to an excess of molybdenum in the synthesis charge. Fig. 2 shows the diffractograms of the iron-containing HDS catalysts after 20 hours on stream. The different phases present in all the samples as determined by X-ray diffraction and the BET surface areas of the fresh catalysts are presented in Table 1.

All the iron-promoted catalysts consisted of a mixture of crystalline phases. 


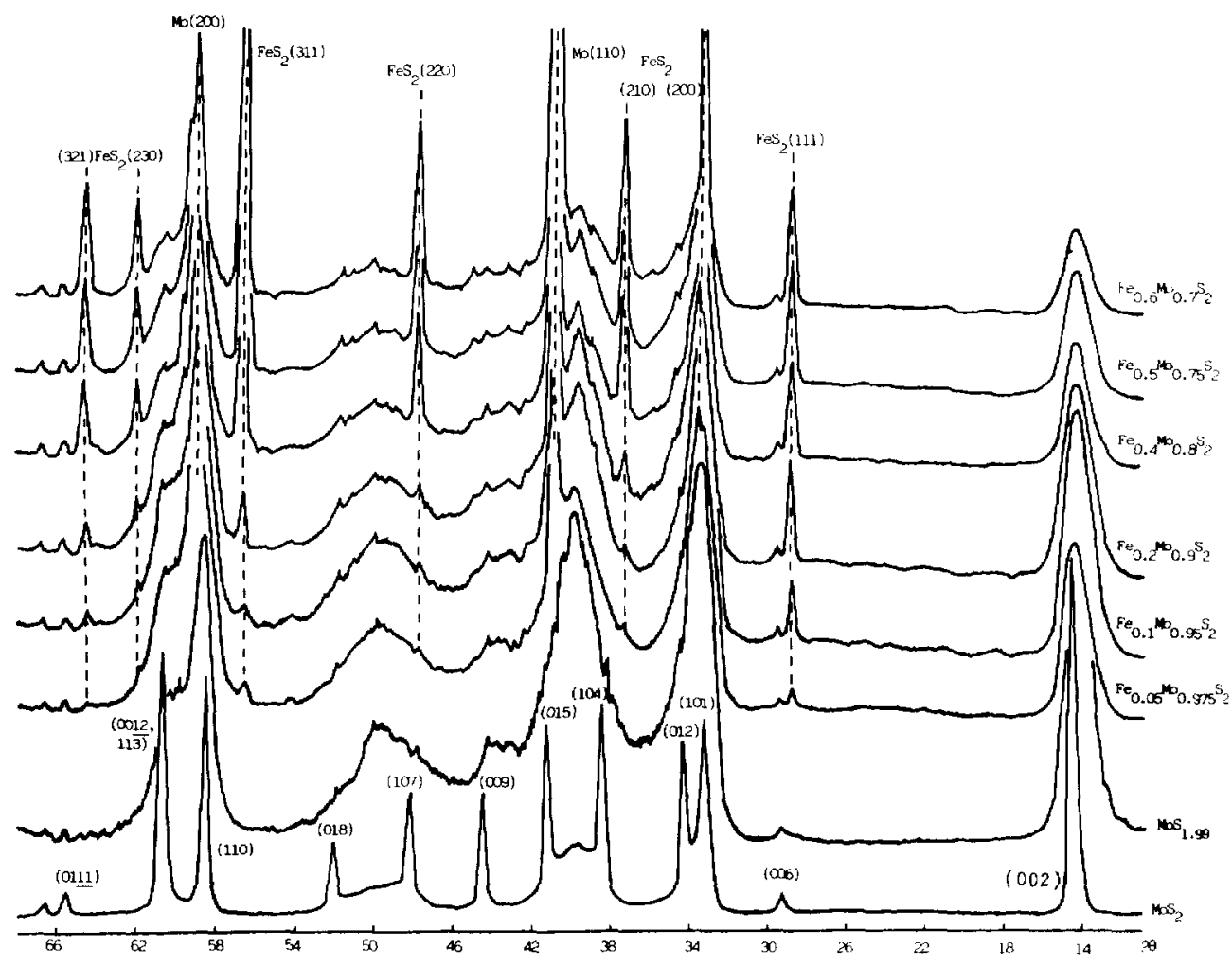

Fig. 1. X-ray diffraction patterns of freshly prepared catalysts $\mathrm{Fe}_{0.05} \mathrm{Mo}_{0.975} \mathrm{~S}_{2}, \mathrm{Fe}_{0.1} \mathrm{Mo}_{0.95} \mathrm{~S}_{2}$, $\mathrm{Fe}_{0.2} \mathrm{Mo}_{0.9} \mathrm{~S}_{2}, \mathrm{Fe}_{0.4} \mathrm{Mo}_{0.8} \mathrm{~S}_{2}, \mathrm{Fe}_{0.5} \mathrm{Mo}_{0.75} \mathrm{~S}_{2}$, and $\mathrm{Fe}_{0.6} \mathrm{Mo}_{0.7} \mathrm{~S}_{2}$. For comparison, the diffraction patterns of $\mathrm{MoS}_{2}$ and $\mathrm{MoS}_{1.99}$ are also shown.

Samples $\mathrm{Fe}_{0.05} \mathrm{Mo}_{0.975} \mathrm{~S}_{2}, \mathrm{Fe}_{0.1} \mathrm{Mo}_{0.95} \mathrm{~S}_{2}, \mathrm{Fe}_{0.2} \mathrm{Mo}_{0.9} \mathrm{~S}_{2}, \mathrm{Fe}_{0.4} \mathrm{Mo}_{0.8} \mathrm{~S}_{2}, \mathrm{Fe}_{0.5} \mathrm{Mo}_{0.75} \mathrm{~S}_{2}$, and $\mathrm{Fe}_{0.6} \mathrm{Mo}_{0.7} \mathrm{~S}_{2}$ showed similar XRD patterns (Fig. 1) corresponding to a mixture of unreacted molybdenum, $\mathrm{FeS}_{2}$ with a pyrite-type structure, and a third phase exhibiting broad diffraction lines. The $\mathrm{FeS}_{2}$ phase showed a progressive growth with increasing iron loadings. The diffraction pattern of the third phase found in the catalysts is characteristic of a poorly crystallized material. Compared to stoichiometric $\mathrm{MoS}_{2}$ (Fig. 1) this phase exhibited broader diffraction lines and there were also differences in the intensities of reflections from certain crystallographic planes. The diffraction maxima and the line widths of this phase closely matched those of the sulfur deficient $\mathrm{MoS}_{1.99}$ or $\mathrm{MoS}_{1.95}$ (Fig. 1). Therefore, the X-ray diffraction patterns of this third phase could be attributed to the presence of a non-stoichiometric molybdenum sulfide phase.

The presence of a similar, sulfur-deficient molybdenum sulfide phase in highly active cobalt-promoted HDS catalysts was recently reported by our group 


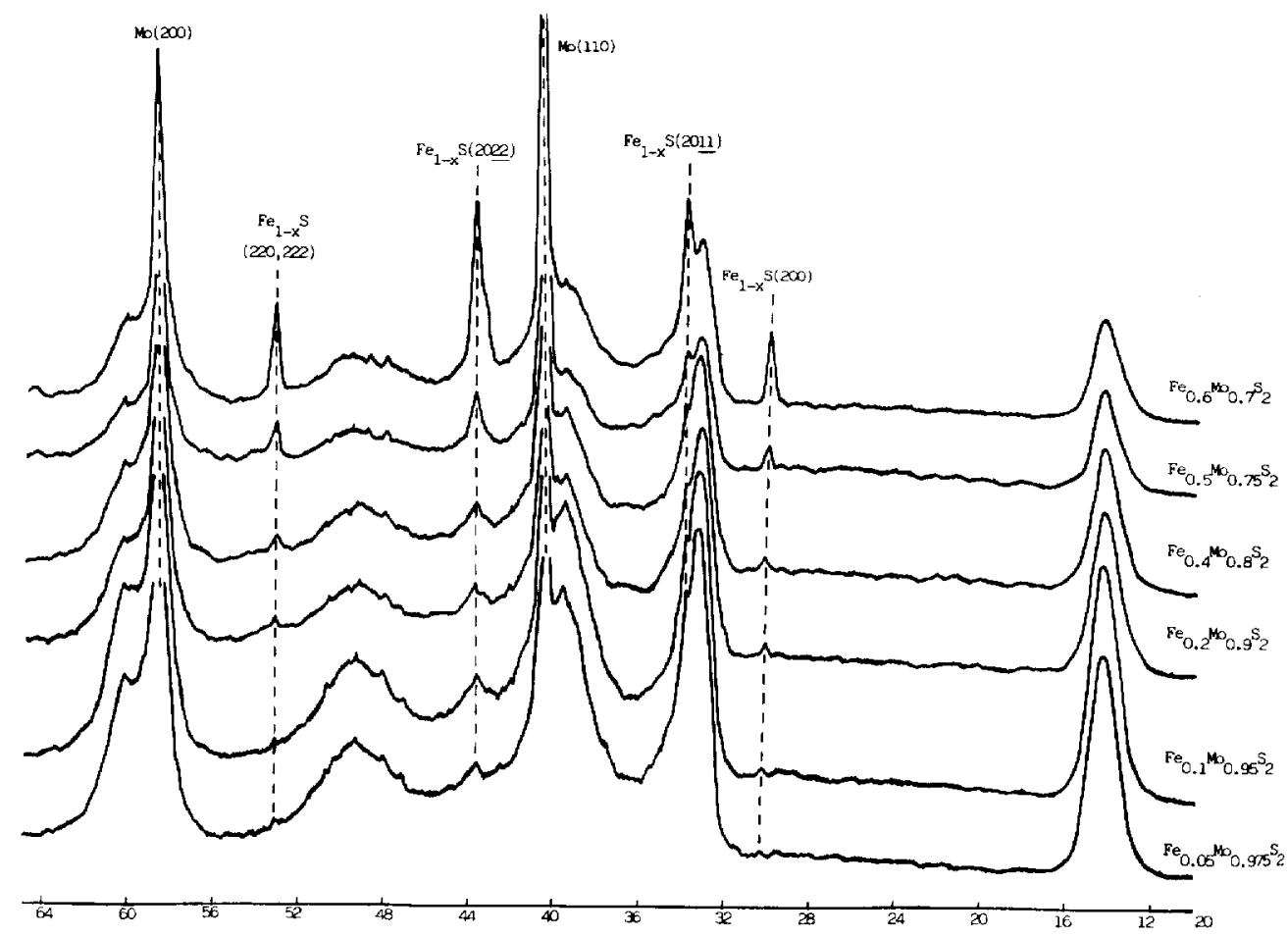

Fig. 2. X-ray diffraction patterns of catalysts $\mathrm{Fe}_{0.05} \mathrm{Mo}_{0.975} \mathrm{~S}_{2}, \mathrm{Fe}_{0.1} \mathbf{M o}_{0.95} \mathrm{~S}_{2}, \mathrm{Fe}_{0.2} \mathrm{Mo}_{0.9} \mathrm{~S}_{2}$, $\mathrm{Fe}_{0.4} \mathrm{Mo}_{0.8} \mathrm{~S}_{2}, \mathrm{Fe}_{0.5} \mathrm{Mo}_{0.75} \mathrm{~S}_{2}$, and $\mathrm{Fe}_{0.6} \mathrm{Mo}_{0.7} \mathrm{~S}_{2}$ after prolonged exposure to typical hydrodesulfurization reaction conditions in a flow reactor.

\section{TABLE 1}

BET surface areas and phases detected in XRD

\begin{tabular}{lllll}
\hline Catalyst & $\begin{array}{l}\text { Fe/Mo } \\
\text { (atomic ratio })\end{array}$ & $\begin{array}{l}\text { BET Surface Area } \\
\left(\mathrm{m}^{2} / \mathrm{g}\right)\end{array}$ & \multicolumn{2}{l}{ Crystalline Phases $^{b}$} \\
\cline { 3 - 6 } & & 15 & Fresh Catalyst & Used Catalyst \\
\hline $\mathrm{Fe}_{0.05} \mathrm{Mo}_{0.975} \mathrm{~S}_{2}$ & 0.051 & 21 & $\mathrm{Mo}+\mathrm{FeS} \mathrm{S}_{2}+\mathrm{A}^{a}$ & $\mathrm{Mo}+\mathrm{Fe}_{1-x} \mathrm{~S}+\mathrm{A}$ \\
$\mathrm{Fe}_{0.1} \mathrm{Mo}_{0.95} \mathrm{~S}_{2}$ & 0.105 & 16 & $\mathrm{Mo}+\mathrm{Fe} \mathrm{S}_{2}+\mathrm{A}$ & $\mathrm{Mo}+\mathrm{Fe}_{1-x} \mathrm{~S}+\mathrm{A}$ \\
$\mathrm{Fe}_{0.2} \mathrm{Mo}_{0.9} \mathrm{~S}_{2}$ & 0.222 & 20 & $\mathrm{Mo}+\mathrm{FeS}_{2}+\mathrm{A}$ & $\mathrm{Mo}+\mathrm{Fe}_{1-x} \mathrm{~S}+\mathrm{A}$ \\
$\mathrm{Fe}_{0.4} \mathrm{Mo}_{0.8} \mathrm{~S}_{2}$ & 0.353 & 6 & $\mathrm{Mo}+\mathrm{FeS}_{2}+\mathrm{A}$ & $\mathrm{Mo}+\mathrm{Fe}_{1-x} \mathrm{~S}+\mathrm{A}$ \\
$\mathrm{Fe}_{0.5} \mathrm{Mo}_{0.75} \mathrm{~S}_{2}$ & 0.667 & 6 & $\mathrm{Mo}+\mathrm{FeS}_{2}+\mathrm{A}$ & $\mathrm{Mo}+\mathrm{Fe}_{1-\mathrm{x}} \mathrm{S}+\mathrm{A}$ \\
$\mathrm{Fe}_{0.6} \mathrm{Mo}_{0.7} \mathrm{~S}_{2}$ & 0.8571 & 1 & $\mathrm{Mo}+\mathrm{FeS}_{2}+\mathrm{A}$ & $\mathrm{Mo}+\mathrm{Fe}_{1-\mathrm{x}} \mathrm{S}+\mathrm{A}$ \\
$\mathrm{Fe}_{0.2} \mathrm{Mo}_{0.9}+\mathrm{H}_{2} \mathrm{~S}$ & 0.222 & 1 & $\mathrm{Mo}_{\mathrm{Fe}} \mathrm{F}$ & $\mathrm{Mo}_{1-x}+\mathrm{Fe}_{1-\mathrm{x}} \mathrm{S}$ \\
$\mathrm{MoS}_{2}$ & 0 & 20 & $\mathrm{MoS}_{2}$ & $\mathrm{MoS}_{2}$ \\
$\mathrm{MoS}_{1.95}$ & 0 & $\mathrm{MoS}_{2}+\mathrm{Mo}$ & $\mathrm{MoS}_{2}+\mathrm{Mo}$ \\
\hline
\end{tabular}

${ }^{a} \mathrm{~A}$ is a non-stoichiometric $\mathrm{MoS}_{2}$ based phase

${ }^{b}$ The phases in italics are present in only minor proportion or as traces. 

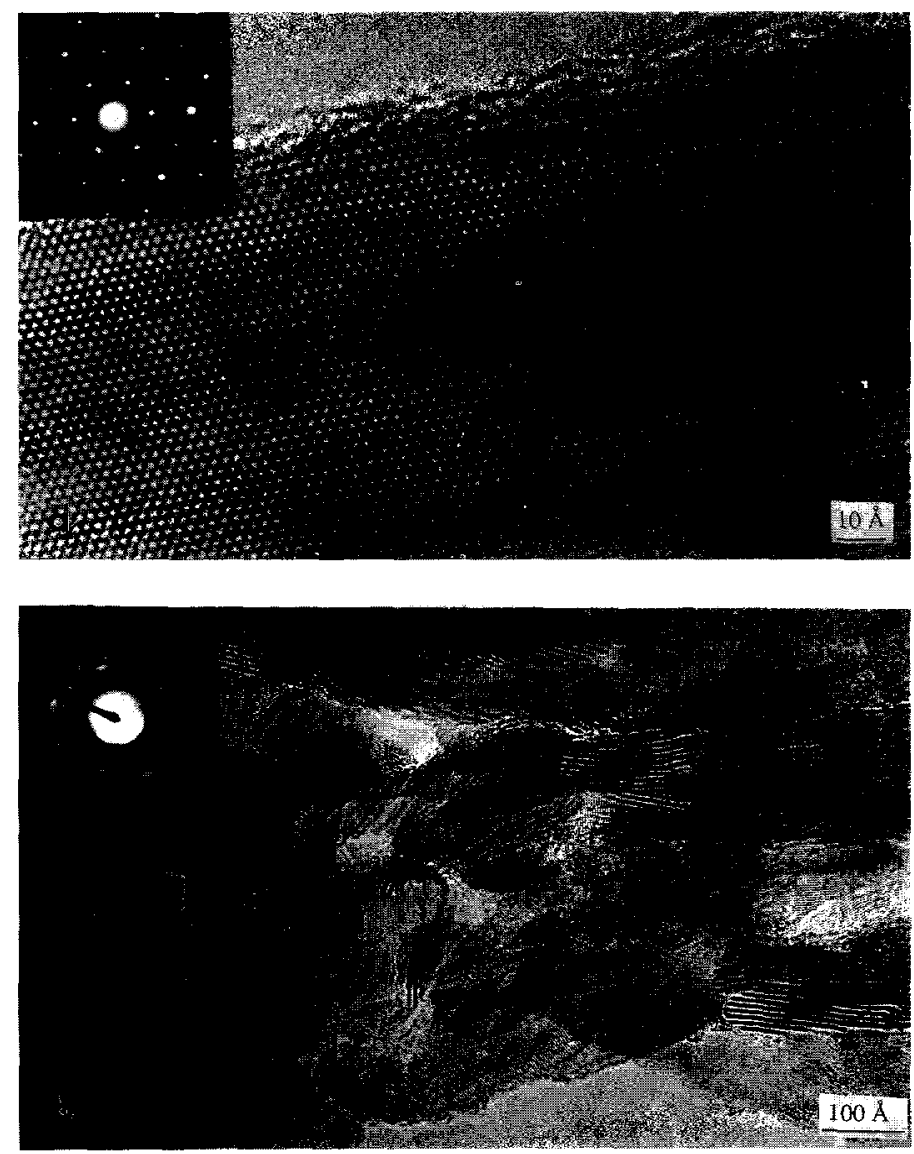

Fig. 3A, B.

[25]. The formation of this phase was explained by assuming that during the synthesis of the catalysts by solid state reaction there was a partial replacement of $\mathrm{Mo}^{4+}$ ions in the $\mathrm{MoS}_{2}$ lattice by promoter cations of a lower charge. The electroneutrality in the lattice was then maintained by creating anion vacancies. In similar fashion, the iron promoter could behave as an aliovalent impurity doping the $\mathrm{MoS}_{2}$ crystals to generate the non-stoichiometric phase. However, solid state work done by D'Ambra et al. [32] argues against this scenario of the promoter ion substituting directly into the $\mathrm{MoS}_{2}$ lattice. It seems possible that the iron acts as a scavenger during the solid state synthesis, forming bulk iron sulfides and leaving less sulfur available for the formation of $\mathrm{MoS}_{2}$, leading to the formation of a non-stoichiometric bulk molybdenum sulfide phase.

The X-ray diffraction pattern of sample $\mathrm{Fe}_{0.2} \mathrm{Mo}_{0.9}+\mathrm{H}_{2} \mathrm{~S}$ showed the presence of two phases, metallic molybdenum inert to the sulfiding treatment un- 

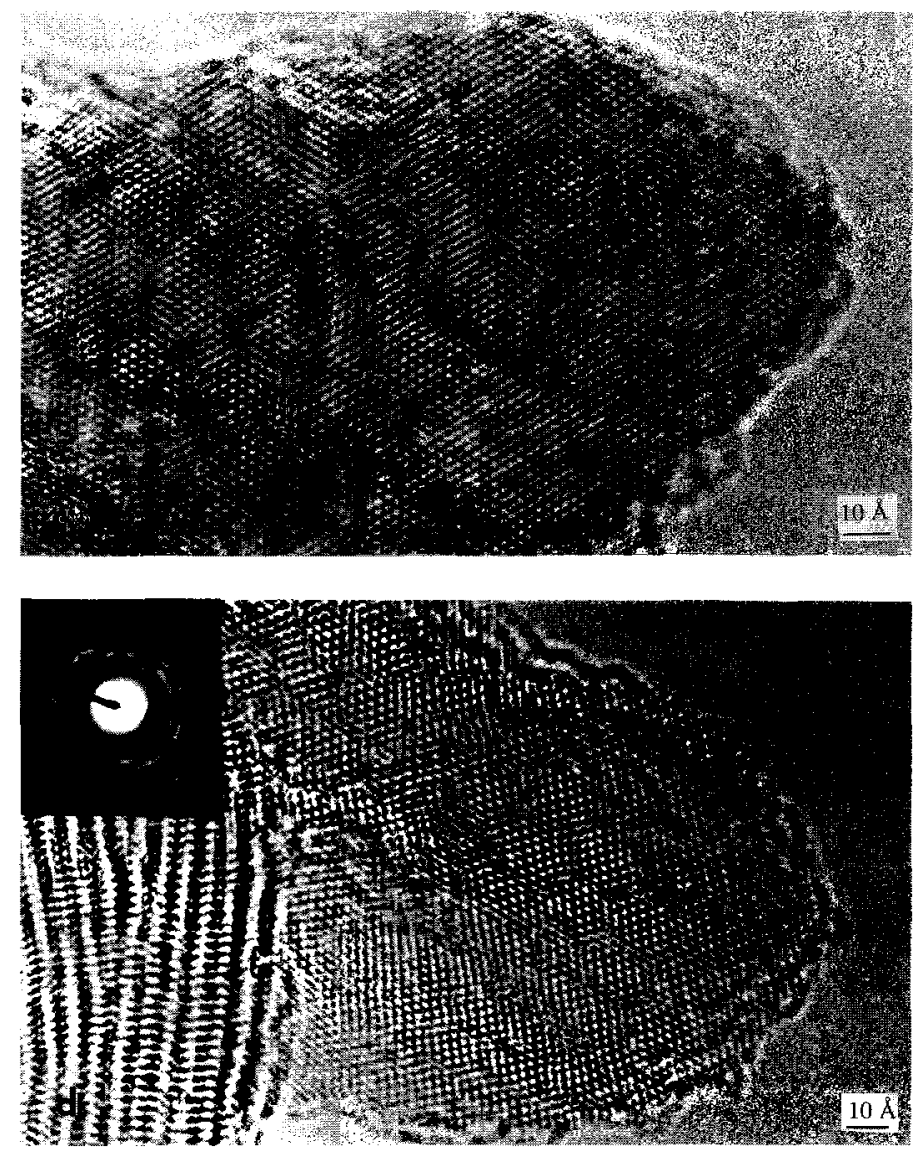

Fig. 3C, D.

der an $\mathrm{H}_{2} \mathrm{~S} / \mathrm{H}_{2}$ flow at $673 \mathrm{~K}$ and $\mathrm{Fe}_{1-\mathrm{x}} \mathrm{S}$ which is an iron sulfide phase also known as pyrrhotite. The broad peaks associated with the non-stoichiometric molybdenum sulfide phase were not present in the $\mathrm{X}$-ray powder patterns of the presulfided mechanical mixture.

The diffractograms of the used catalysts (Fig. 2) contained a mixture of three phases: metallic molybdenum, the non-stoichiometric $\mathrm{MoS}_{2}$, and iron sulfide with a pyrrhotite type structure. It seems that under reaction conditions the $\mathrm{FeS}_{2}$ phase is transformed into the more stable $\mathrm{Fe}_{1-\mathrm{x}} \mathrm{S}$ phase. We cannot rule out the presence of highly dispersed metallic iron with particle sizes or concentrations below the detection limits of XRD.

Electron microscopy confirmed the $\mathrm{X}$-ray diffraction findings. The high resolution micrographs and electron diffraction patterns of the stoichiometric $\mathrm{MoS}_{2}$ sample indicated that the material was crystalline with excellent long 

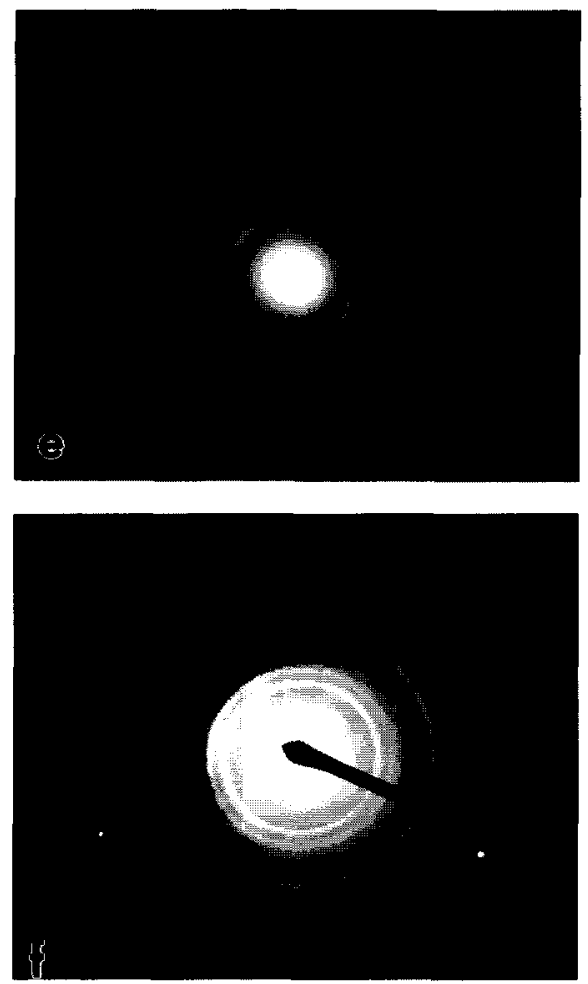

Fig. 3. (a) HREM image of stoichiometric $\mathrm{MoS}_{2}$ illustrating the high degree of crystallinity and long range order found in this catalyst. Inset: Selected-area electron diffraction (SAED) pattern showing well defined diffraction spots. (b) HREM image of non-stoichiometric $\mathrm{MoS}_{1.95}$ in which the low degree of crystallinity and highly disordered structure are clearly visible. Inset: SAED pattern showing difraction rings indicating its polycrystalline nature. (c) A highly magnified HREM image of a region in $\mathrm{MoS}_{1.95}$ showing the presence of defects along the edge planes. (d) HREM image of the molybdenum disulfide region of $\mathrm{Fe}_{0.1} \mathrm{Mo}_{0.95} \mathrm{~S}_{2}$. As in $\mathrm{MoS}_{1.95}$, the defects are present mainly on the $\mathrm{MoS}_{2}$ edge planes. Note the close similarity with the $\mathrm{MoS}_{1.95}$ sample shown in Fig. 3c. Inset: SAED pattern showing the ring structure indexed as $\mathrm{MoS}_{2}$. (e) SAED patterns from $\mathrm{Fe}_{0.05} \mathrm{Mo}_{(0.975)} \mathrm{S}_{2}$. The (002), (101), (103), and (107) reflections have the greatest intensities. (f) SAED patterns from a different region of $\mathrm{Fe}_{0.05} \mathrm{Mo}_{0.975} \mathrm{~S}_{2}$. In this case, the (101), (103), and (107) reflections have the greatest intensities.

range order, yielding sharp electron diffraction spots as a result of Bragg diffraction from the highly ordered planes of $\mathrm{MoS}_{2}$ (Fig. 3a).

The polycrystalline, defect-rich nature of the iron-containing samples and of the $\mathrm{MoS}_{1.95}$ sample may be plainly seen in the other micrographs (Figs. $3 \mathrm{~b}$, $3 \mathrm{c}, 3 \mathrm{~d}, 3 \mathrm{e}$ and $3 \mathrm{f}$ ). It is clear that the non-stoichiometric and the iron samples are very disordered with a high defect concentration. The electron diffraction patterns from these regions reflect the lack of uniform periodic structure as concentric rings instead of well defined spots are formed by the diffracted electron beam. From optical diffraction patterns obtained by passing a Laser beam 

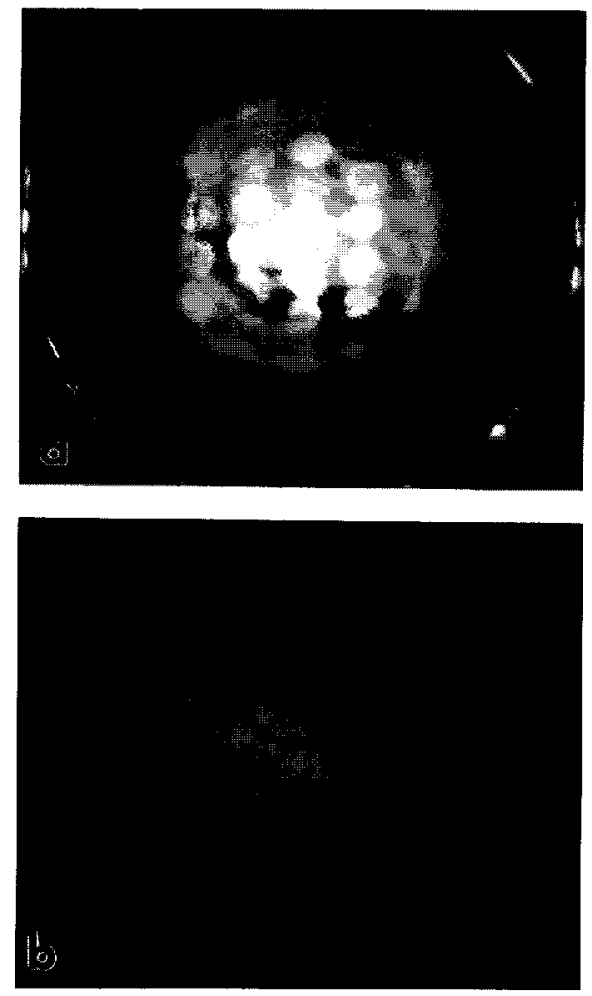

Fig. 4 (a) Convergent beam pattern taken from a particle in the $\mathrm{Fe}_{0.05} \mathrm{Mo}_{0.975} \mathrm{~S}_{2}$ sample. This pattern is indexed as the [213] zone axis of cubic $\mathrm{FeS}_{2}$. (b) Convergent beam pattern taken from a particle in the $\mathrm{Fe}_{0.06} \mathrm{Mo}_{0.7} \mathrm{~S}_{2}$ sample. This pattern is indexed as the [112] zone axis of cubic $\mathrm{FeS}_{2}$.

through the structure images we infer that the $(10 \overline{1} 0),(10 \overline{1} 1),(10 \overline{1} 2)$ planes of molybdenum disulfide are present in these disordered regions. These planes represent the edges of $\mathrm{MoS}_{2}$ crystals. It was also found that by and large these disordered regions were localized on these edge planes and not on the basal planes. According to the microscopy results, the average crystallite size for these materials was essentially constant. Thus, we believe the electron diffraction studies are indicative of a highly defective, sulfur deficient material rather than of a sample consisting of many small crystallites diffracting incoherently with respect to each other. The work of Ergun [33] supports this claim. It appears that either the addition of iron or a deliberate lack of sulfur during synthesis leads to a surface roughening of the catalyst morphology and higher catalytic activity.

In addition to the highly defective $\mathrm{MoS}_{2}$ regions observed in the iron containing samples, we were also able to identify by electron diffraction the catalyst regions containing the $\mathrm{FeS}_{2}$ phase detected by X-ray diffraction and en- 
ergy dispersive spectroscopy. Figs. $4 \mathrm{a}$ and $4 \mathrm{~b}$ provide an example of convergent beam electron diffraction patterns taken from such regions in the $\mathrm{Fe}_{0.05} \mathrm{Mo}_{0.975} \mathrm{~S}_{2}$ and $\mathrm{Fe}_{0.6} \mathrm{Mo}_{0.7} \mathrm{~S}_{2}$ samples, respectively. Electron microscopy gave no evidence for the presence of metallic iron particles. It should be noted that high resolution electron microscopy would allow the identification of metallic iron particles as small as 1-2 $\mathrm{nm}$ in diameter dispersed within the molybdenum sulfide crystallites. Such particles are clearly absent. However, atomically dispersed iron or metallic iron clusters containing a few atoms would not show up in the high resolution micrographs.

The temperature dependence of HDS activity of the model catalysts is presented in Fig. 5. All iron-containing samples displayed high activity similar to that of sulfur-deficient $\mathrm{MoS}_{1.95}$. The pure, bulk synthesized $\mathrm{MoS}_{2}$ which contained highly crystalline, nearly defect-free $\mathrm{MoS}_{2}$ crystals was relatively inactive. The presulfided mechanical mixture " $\mathrm{Fe}_{0.2} \mathrm{Mo}_{0.9}+\mathrm{H}_{2} \mathrm{~S}$ " containing metallic molybdenum and pyrrhotite was much less active then the solid state synthesized iron catalysts. The highly active iron-containing samples are grouped together with the data for the non-stoichiometric $\mathrm{MoS}_{1.95}$ sample in the shaded area on top of Fig. 5. The less active $\mathrm{Fe}_{0.2} \mathrm{Mo}_{0.9}+\mathrm{H}_{2} \mathrm{~S}$ and $\mathrm{MoS}_{2}$ are grouped in the cross-hatched area below. These results show that iron, although not being an electronic promoter in the classic sense [24], can lead to

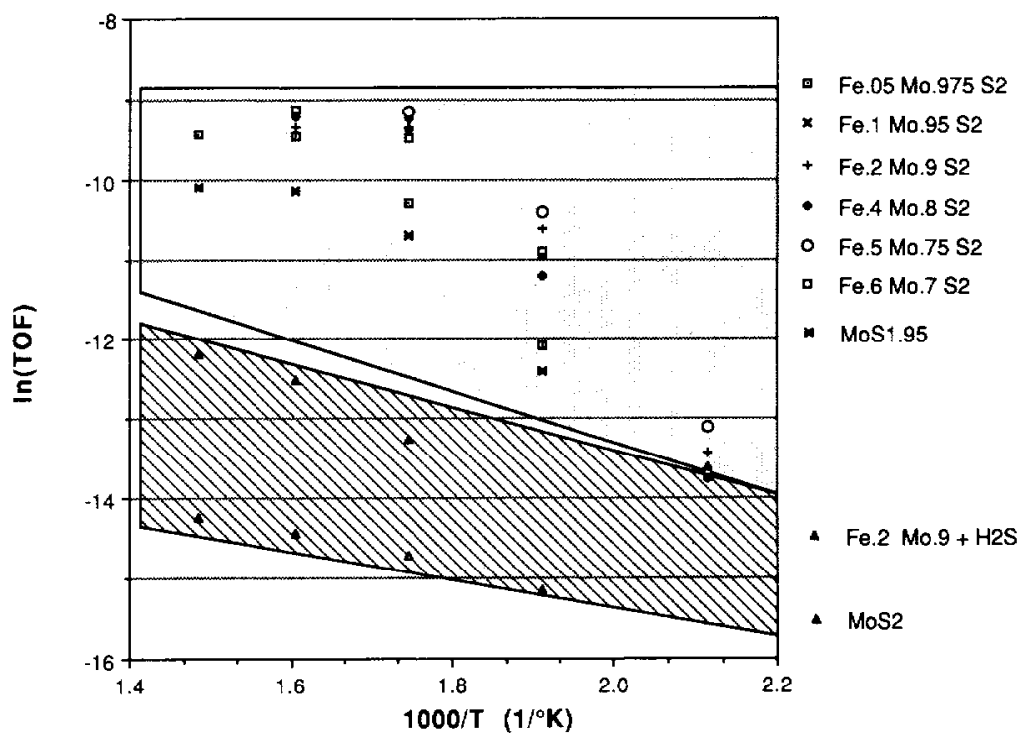

Fig. 5. Plot of HDS activity (ln (TOF)) vs. $1 / T$ for model catalysts. The turnover frequencies shown are normalized on the basis of moles of thiophene converted per mole of Mo in the catalyst per second and should be considered as "quasi-turnover frequencies" since we do not have any information concerning the actual number of active sites. 
structural changes in molybdenum sulfide resulting in enhanced HDS activity. Interestingly, the iron-containing samples with very high activity had a wide range of surface areas from 6 to $21 \mathrm{~m}^{2} / \mathrm{g}$ (Table 1), yet the HDS activity of the catalysts remained at similar high levels. These findings support the notion that HDS activities do not scale with BET surface areas. A comparison of the activities of iron, cobalt, nickel and copper-containing molybdenum sulfide solid state catalysts is given in Table 2. Irrespective of the nature of the second metal, very similar activities were found. These activities fall into the same range as the one displayed by the $\mathrm{MoS}_{1.95}$ sample. This similarity lends strong support to the hypothesis that the enhanced activity of the solid state catalysts is primarily due to the presence of nonstoichiometric molybdenum sulfide, while the classic promoter effect of the second metal component might at best manifest itself as a secondary effect.

The product distributions of different hydrocarbons resulting from the hydrodesulfurization of thiophene are given in Fig. 6. All data shown in this figure were collected within a narrow range of turnover frequencies at comparable levels of conversion. Isobutene and butadiene could not be separated under our experimental conditions and Fig. 6 shows the sum of these two products.

Differences in product distributions were observed among the catalysts. The iron-containing materials yielded $\mathrm{C}_{4}$ products, the majority of which were $\mathrm{n}$-butane, followed by trans-2-butene, cis-2-butene, and 1-butene in abundance. It was also observed that increasing iron concentration resulted in decreasing $\mathrm{n}$-butane yield while simultaneously increasing the amounts of butenes produced. The non-stoichiometric $\mathrm{MoS}_{1.95}$ produced the most $\mathrm{n}$-butane and less of the unsaturated butenes (Fig. 6). We believe this high selectivity on $\mathrm{n}$-butane is due to the presence of unreacted molybdenum in the catalyst sample. However, the trend within the iron series toward increasing alkene formation with increasing iron content indicates that though iron may be responsible for the creation of non-stoichiometry in the highly active samples, it

TABLE 2

Comparison of activity of iron cobalt, nickel and copper containing solid state catalysts at $573 \mathrm{~K}$

\begin{tabular}{ll}
\hline Catalyst & \multicolumn{2}{l}{ Turnover Frequency } \\
\cline { 2 - 2 } & (moles thiophene/mole $\left.\mathrm{Mo} / \mathrm{s} \times 10^{-5}\right)$ \\
\hline $\mathrm{Fe}_{0.1} \mathrm{Mo}_{0.95} \mathrm{~S}_{2}$ & 8.11 \\
$\mathrm{Co}_{0.1} \mathrm{Mo}_{0.95} \mathrm{~S}_{2}$ & 8.20 \\
$\mathrm{Ni}_{0.1} \mathrm{Mo}_{0.90} \mathrm{~S}_{2}$ & 1.15 \\
$\mathrm{Cu}_{0.1} \mathrm{Mo}_{0.95} \mathrm{~S}_{2}$ & 3.12 \\
$\mathrm{MoS}_{1.95}$ & 2.22 \\
$\mathrm{MoS}_{2}$ & 0.0316 \\
\hline
\end{tabular}




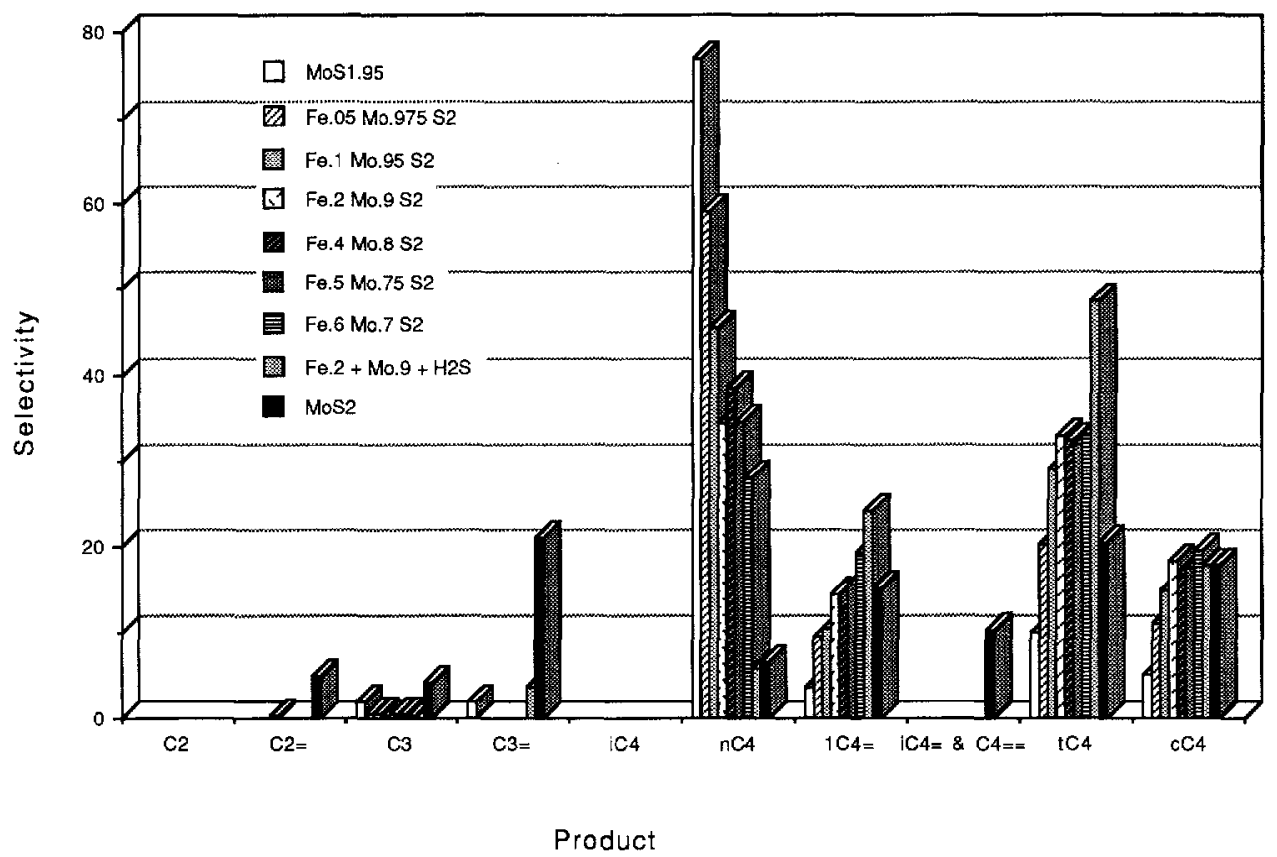

Fig. 6. Selectivity for $\mathrm{C}_{2}, \mathrm{C}_{3}$ and $\mathrm{C}_{4}$ hydrocarbon product formation in thiophene hydrodesulfurization at $523 \mathrm{~K}$.

also favors the formation of unsaturated products. At iron-to-molybdenum ratios above 0.222 this trend may be seen to level off as further addition of iron to the sample does not produce as large a change in product distributions. Based on our selectivity patterns, one cannot completely rule out some electronic implications of iron.

The $\mathrm{MoS}_{2}$ and $\mathrm{Fe}_{0.2} \mathrm{Mo}_{0.9+\mathrm{H}_{2}} \mathrm{~S}$ were the only samples to produce any $\mathrm{C}_{2}$ or $\mathrm{C}_{3}$ products in noticeable quantities. The major component for both of these catalysts was trans-2-butene, though the stoichiometric $\mathrm{MoS}_{2}$ did yield a significant quantity of propylene as well as butadiene and/or isobutene.

\section{CONCLUSIONS}

Unsupported highly active iron-promoted HDS catalysts have been prepared by a solid state reaction of elemental iron, molybdenum and sulfur at $783 \mathrm{~K}$. High catalytic activity for HDS of thiophene coincided with the presence of a non-stoichiometric phase. X-ray diffraction and electron microscopy results showed that this phase is very similar to non-stoichiometric, sulfurdeficient molybdenum sulfide. It may be inferred that the primary role of iron in this system is to aid the formation of bulk iron sulfides during the solid state 
synthesis, thereby depleting the synthesis mixture of the sulfur required for the formation of stoichiometric $\mathrm{MoS}_{2}$. This leads to a catalyst morphology displaying a highly disordered structure with very irregular, nonuniform surfaces. The results presented here are in excellent agreement with previous studies on solid state molybdenum sulfide catalysts containing cobalt, nickel or copper [25-27] where the presence of a similar, non-stoichiometric molybdenum sulfide phase coincided with greatly enhanced HDS activity.

\section{ACKNOWLEDGEMENTS}

M.A. Villa Garcia wishes to express her gratitude to the MEC/Fulbright Committee for financial support.

\section{REFERENCES}

1 B.C. Gates, J.R. Katzer and G.C.A. Schuit, Chemistry of Catalytic Processes, McGraw Hill, New York, 1979, Chapter 5.

2 R.J.H. Voorhoeve and J.C.M. Stuiver, J. Catal., 23 (1971) 243.

3 A.L. Farragher and P. Cossee, Catalytic Chemistry of Mo and W Sulfides and Related Ternary Compounds, in J.W. Hightower (Ed.), Proc. $5^{\text {th }}$ Int. Congress on Catalysis, Palm Beach, FL, August 20-26, 1972, Elsevier North-Holland, Amsterdam, 1973, p. 1301.

4 G. Hagenbach, P. Courty and B. Delmon, J. Catal., 31 (1973) 264.

5 D. Pirottre, J.M. Zabala, P. Grange and B. Delmon, Bull. Soc. Chim. Belg., 90 (1981) 1239.

6 K.C. Pratt and J.V. Sanders in T. Seiyama and K. Tanabe (Eds.), New Horizons in Catalysis, Studies in Surface Science and Catalysis, Vol. 7, Amsterdam, 1981, p. 1420.

7 M.L. Vrinat and L. De Mourgues, Appl. Catal., 5 (1983) 43.

8 J.P.R. Vissers, V.H.J. de Beer and R. Prins, J. Chem. Soc., Faraday Trans. I. 83 (1987) 2145.

9 R. Prins, S.M.A.M. Bouwens, D.C. Koningsberger and V.H.J. de Beer, EXAFS and XPS of Sulfided $\mathrm{Co}(\mathrm{Ni})-\mathrm{Mo} / \mathrm{C}$ and $\mathrm{Co}(\mathrm{Ni})-\mathrm{Mo} / \mathrm{Al}_{2} \mathrm{O}_{3}$ Catalysts, $11^{\text {th }}$ North American Meeting of the Catalysis Society, Dearborn, MI, May 7-11, 1989.

10 M.J. Ledoux, O. Michaux, G. Agostini and P. Panissod, J. Catal., 96 (1985) 189.

11 M.J. Ledoux, O. Michaux, G. Agostini and P. Panissod, J. Catal., 102 (1986) 275.

12 H. Topsøe, B.S. Clausen, R. Candia, C. Wivel and S. Mørup, J. Catal., 68 (1981) 433.

13 C. Wivel, R. Candia, B.S. Clausen, S. Mørup and H. Topsøe, J. Catal., 68 (1981) 453.

14 M. Breysse, M. Lacroix and M. Vrinat, Mixed Unsupported Hydrotreating Catalysts Prepared by Complex Decomposition or Combination of the Elements, $11^{\text {th }}$ North American Meeting of the Catalysis Society, Dearborn, MI, May 7-11, 1989.

15 W. Eltzner, M. Breysse, M. Lacroix, C. Leclercq and M. Vrinat, Polyhedron, $7(22,23)$ (1988) 2405.

16 D.S. Thakur, P. Grange and B. Delmon, J. Less-Common Metals, 64 (1979) 201.

17 D.S. Thakur, J. Catal., 94 (1985) 310.

18 S. Harris, Polyhedron, 5 (1986) 151.

19 S. Göbölös, Q. Wu, A. Loivier, F. Delannay and B. Delmon, J. Chem. Soc., Faraday Trans. I, 82 (1983) 2423.

20 S. Göbölös, Q. Wu, A. Loivier, F. Delannay, P. Grange, B. Delmon and J. Ladriere, Polyhedron, 5 (1986) 219. 
21 E.E. Donati, Advances in Catalysis and Related Subjects, Vol. 8, Academic Press; New York, 1956, p. 39.

22 S. Göbölös, W. Qin, O. Andre, F. Delannay and B. Delmon, J. Chem. Soc., Faraday Trans. I, 82 (1986) 2423.

23 F. Delannay, D.S. Thakur and B. Delmon, J. Less-Common Metals, 63 (1979) 265.

24 S. Harris and R. Chianelli, J. Catal., 98 (1986) 17.

25 M.A. Villa-Garcia, J. Lindner, A. Sachdev and J. Schwank, J. Catal., 119 (1989) 388.

26 J. Lindner, M.A. Villa-Garcia, A. Sachdev and J. Schwank, J. Chem. Soc. Chem. Comm., submitted for publication.

27 J. Lindner, A. Sachdev, M.A. Villa-Garcia and J. Schwank, J. Catal., 120 (1989) in press.

28 E.G. Derouane, E. Pederson, B.S. Clausen, Z. Gabelica, R. Candia and H. Topsøe, J. Catal., 99 (1986) 253.

29 G. Hagenbach, P. Courty and B. Delmon, J. Catal., 23 (1971) 295.

30 R. Candia, B.S. Clausen and H. Topsøe, Bull. Soc. Chim. Belg., 90 (1981) 1225.

31 S. Göbölös, Q. Wu and B. Delmon, Appl. Catal., 1 (1984) 89.

32 D.M. D'Ambra, J.V. Marzik, R. Kershaw, J. Baglio, K. Dright and A. Wold, J. Solid State Chem., 57 (1985) 351.

33 S. Ergun, Phys. Rev., B1 (1970) 3371. 